\title{
Children's Voices: Perspectives on Using Assistive Technology
}

\author{
Robin E. Schock \\ St. Lawrence College \\ Elizabeth A. Lee \\ Queen's University
}

\begin{abstract}
Rarely are the views of children with learning disabilities elicited. In this study, we used focus groups involving eight students with learning disabilities to explore their self-perceptions as learners and writers using assistive technology (AT). Three groups of two to three Grade 4-8 students and their parents participated in the qualitative study. Both student and parent responses provided data for thematic analysis that resulted in three themes: (a) changes in students' self-perceptions as learners; (b) student and parental self-reported benefits of using assistive technology; and (c) inconsistencies in approaches to using assistive technology in schools. The implications for education are greater attention to the views of elementary school children; greater focus on the use of AT in the classroom; and greater AT training for teachers in order to better support the use of AT by students with $L D$.
\end{abstract}

Mainstream classrooms have experienced an increased use of assistive technology (AT) by students who face a variety of learning challenges. This study explored student and parental perceptions of the role that AT played in the learning of students identified as having learning disabilities (LD). Eight elementary school students with LD participated in focus groups that explored their self-perceptions as learners and writers using AT. Their parents also participated in focus groups. For this research, the following definition of LD was adopted:

Learning Disabilities refer to a number of disorders which may affect the acquisition, organization, retention, understanding or use of verbal or nonverbal information. These disorders affect learning in individuals who otherwise demonstrate at least 
average abilities essential for thinking and/or reasoning. As such, learning disabilities are distinct from global intellectual deficiency (Learning Disabilities Association of Canada, 2002).

\section{Writing}

Writing is a powerful predictor of academic success, and as a complex procedure it requires multiple processes to work simultaneously (Torrance, 2007; Torrance \& Jeffery, 1999); this with its recursive nature involves the simultaneous application of varied types of knowledge (Hayes, 2004). These multiple forms of knowledge include topical knowledge needed to generate and organize ideas, knowledge of the potential audience and genres, and the vocabulary required to express these ideas (Hayes, 2004). To become expert writers students need to acquire knowledge and skills across these components along with the ability to coordinate them (Torrance, 2007).

Text production interacts with the writer's expertise, content knowledge, and with the nature of the writing task (Hayes, 2004; Torrance \& Jeffery, 1999). Executive control and self-regulation play a role in effective writing (Graham \& Harris, 2000), as does the effective use of working memory resources (Torrance, 2007). Society's demand for increasingly higher levels of literacy skills places students who are unable to write effectively at a disadvantage (Troia, 2005).

\section{Writing Challenges for Students with LD}

Children with learning disabilities find the task of writing exasperating, if not impossible (Goddard \& Sendi, 2008). They face many difficulties, one being a limited capacity to maintain multiple items in working memory (Swanson, Harris, \& Graham, 2003). Struggles with writing are compounded by processing difficulties, rapid naming speed impairments, and dysgraphia (difficulty with handwriting/transcription) in written expression (Santangelo, Harris, \& Graham, 2008). The lack of automaticity in transcription skills results in greater cognitive load during writing: thus leaving less memory capacity for other aspects of the task (Swanson et al., 2003). A preoccupation with spelling, grammar, punctuation, and letter formation interferes significantly with students' written product (Santangelo et al., 2008; Swanson et al., 2003), resulting in written content that is minimized or disjointed, as so much time and effort has been spent on transcription (Graham \& Harris, 2000). Revision strategies are also affected for students with LD; less than $20 \%$ of revisions represent any substantive changes to the original text (MacArthur \& Graham, 1987; Santangelo et al., 2008). The ability to apply evaluation criteria to their writing may be inaccurate as well as their ability to distinguish errors or identify what the audience requires (Swanson et al., 2003).

\section{Assistive Technology}

AT has been defined as any technology with the potential to enhance the performance of persons with disabilities (Lewis, Graves, Ashton, \& Kieley, 1998). Word predictive software (WPS) addresses several of the challenges that students with LD face when writing. The natural language used in WPS such as Co:Writer and WordQ allow 
visual and auditory cueing systems to assist the writer with text composition (Shein, Nantais, Nishiyama, Tam, \& Marshall, 2001). Words are generated via rules of word frequency and grammar (Handley-More, Deitz, Billingsley, \& Coggins, 2003). Because these programs recognize phonetic spelling in addition to conventional spelling (Evmenova, Graff, Jerome, \& Behrmann, 2010), they may alleviate many writing difficulties for students with LD (Handley-More et al., 2003). WPS has improved the text-entry speed of students with LD (Lewis et al., 1998), while speech synthesis is an added benefit allowing the user to listen to the computer's echo of the typed letters, words or sentences (Tam, Archer, Mays, \& Skidmore, 2005). Other AT products such as Kurzweil Education's text-to-speech software and Dragon NaturallySpeaking speech recognition software also support students with LD in their learning.

\section{Studies Involving WPS}

Participants with physical disabilities. The majority of the research on WPS has been conducted with students with physical disabilities due to the original purpose for its development (Peterson-Karlan, Hourcade, \& Parette, 2008; Tam et al., 2005). For highschool-age students with physical disabilities WPS increased typing speed and accuracy (Tam \& Wells, 2009; Tumlin \& Heller, 2004). For elementary school students the use of WPS improved legibility, number of words spelled correctly, and syntax (Mirenda, Turoldo, \& McAvoy, 2006).

Participants with learning disabilities. A critical review by Batorowicz, Missiuna, and Pollock (2012) listed 28 studies conducted since 1985 that examined technology use by children with LD for writing. The authors' search criteria included peer-reviewed quantitative and qualitative studies of school-age children with LD from Grades 1-12 who used any form of technology for writing. The majority of the studies focused on the evaluation of children's writing in quality and quantity; some measured the speed of writing or the children's behaviour. Findings did suggest some positive behavioural influences on motivation to write and independence in writing when using a variety of technologies. Most studies had inherent methodological problems. Of relevance to the current study are seven word prediction studies: Cullen, Richards, and Frank (2008); Evmenova et al. (2010); Handley-More et al. (2003); Lewis et al. (1998); MacArthur (1998, 1999), and Silio and Barbetta (2010). Most of these studies compared WPS to word processing or handwriting and measured the number of words spelled correctly or the quality of writing in legibility demonstrating improvements in spelling accuracy with WPS. Cullen et al. (2008), while Evmenova et al. (2010) and Lewis et al. (1998) reported improvements in syntax. Evmenova et al. (2010), Handley-More et al. (2003), and Silio and Barbetta (2010) found an increase in the number of words per minute. Evmenova et al. (2010) and Williams (2002) also found increases in text length, while Williams (2002) reported an improvement in the quality of writing using WPS.

The majority of studies to date on AT and students with LD have looked for evidence of academic improvement on some aspect of writing, either in the production of or quality of text. Except for Young (2012) none have directly explored students' perceptions of themselves as learners in the context of using AT. 


\section{Students' Voices}

In fact elementary school students' views are seldom sought. Rarely do researchers involve the children as co-constructors of meaning in research (Conroy \& Harcourt, 2010). Several studies have elicited students' views on topics related to LD but did not involve elementary school students with LD. Brantlinger, Jimenez, Klinger, Pugach, and Richardson (2005) reported several qualitative studies on special education in which participants discussed service provision. Participants included parents, students with developmental disabilities, and siblings of these students, but not a population of elementary students with LD. Curtis, Liabo, Roberts, and Baker (2004) conducted a qualitative study that solicited the direct responses of young people between the ages of 4 to 19 on health service provision. They argued that children's opinions are often not heard, or are ignored due to power imbalances; and parents who might advocate on behalf of their children may be ignored due to marginalization.

Ross (2004) individually interviewed four Grade 8 students with LD followed by a focus group to solicit their perspectives on special education. Students reported positive selfperceptions of living with LD as well as positive views of the support they received from special education services. The postings of children with LD, ages 9 to 18 , to the public website SpeakTop.org. were examined by Raskind, Margalit, and Higgins (2006) to capture the "insider's perspective" of the LD experience. Although respondents did not specifically refer to any support provided by AT, they expressed thoughts about their LD, disclosed academic difficulties, and shared their emotions about being labeled as having LD. Raskind et al. found few positive utterances from the children about their identity as a student with LD. The variation in the findings between Raskind el al. (2006) and Ross (2004) is likely due to the differences in the questions that were used in these qualitative studies.

Evmenova et al. (2010) compared AT programs in a quantitative study. The participants were six campers from Grades 3-6 attending an AT camp. All had severe LD and were introduced to WordQ and Co:Writer. Students' comments were summarized detailing their feelings about how and why they liked each program. Students spoke positively about how AT made writing easier with correct spelling through WPS. More recently, Young (2012) interviewed students with LD and their parents to gain their perspectives on the benefits and challenges of using AT. She found that AT allowed students to persist with school tasks, demonstrate their academic ability, and improve their writing.

\section{Academic Self-Concept of Students with LD}

Research on the self-concept of students with LD presents conflicting points of view, due in part to terms such as self-perceptions, self-concept, and self-esteem being used interchangeably and globally rather than referring to specific aspects of the construct, such as academic, social, or physical self-concept (Elbaum \& Vaughn, 2006). Zeleke's (2004) historical review of the literature on self-concept reported that in the earlier literature it was claimed that both the academic and global self-concepts of students with LD was more negative than those of students who did not have LD. More recent reviews (Elbaum \& Vaughn, 2006; Zeleke, 2004) have stressed the heterogeneity of students with LD and the multi-dimensionality of the construct. The academic self-concept of students 
with LD may be lower than that of their normally achieving peers (Elbaum \& Vaughn, 2006); however, academic self-concept in students with LD varied depending upon the reference group, LD or those without LD (Haager \& Vaughn, 1995). Academic and social self-concept may differ within one student, and the importance of each to the student's global self-esteem varies with age and with how each is measured (Elbaum \& Vaughn, 2006). Most meta-analyses on the global self-concepts of students with LD have found little difference from those of their peers without LD (Burden, 2008; Tabassam \& Grainger, 2002). In this study, self-perception was used to refer to students' perceptions of their academic and social self-concept.

\section{Parents' Perceptions}

The research on parental perceptions has primarily examined parents' understanding of their child's LD. In a critical analysis of this literature Valle (2011) claimed that much of the literature on parents has characterized them as passive recipients of professionals' purported expertise. She argued that the research on parents has focused on parents as subjects who are evaluated on how well they perform their role as parents, not on investigating how they perceive or judge the services provided by the educational system. Those studies that sought parental views of provision of services for students with LD found that parents reported negative perceptions, stating that there was insufficient communication from the educational system and expressing dissatisfaction with the services that were provided (Waggoner \& Wilgosh, 1990).

As an AT trainer, the first author taught elementary students with LD a variety of WPS programs for writing, such as WordQ and Co:Writer. During these one-to-one sessions students reported it was easier to write with the support from the WPS. In follow-up training sessions, four months later, students were often not familiar with the WPS from the previous training session. Some commented that using their laptops at school or at home was not possible but also said AT made writing and school easier.

Knowing that students benefit from the use of AT and that these students had been provided a computer with AT as the result of a formal diagnosis of an LD, we were interested in investigating students' perceptions of the role of AT in their learning and how they described themselves as learners.

As part of a qualitative exploratory study, the research questions were broad. The following research questions were addressed through focus groups with children and parents:

1. How do students with learning disabilities describe themselves as learners?

2. What are the differences between students' experiences at home and at school with how they use their AT?

3. What are the perceptions of students with learning disabilities on how the use of AT contributes to their school experience?

4. What are the parents' perceptions of the role of AT in their son or daughter's education? 


\section{Method}

Focus groups have been identified as one of the few research tools available to obtain data from children (Bickman \& Rog, 1998; Eder \& Fingerson, 2001; Morgan, 1996). Focus groups have been successful in eliciting information from vulnerable populations (Madriz, 2000) and for that reason are valid for use with students with LD (Brantlinger et al., 2005; Eder \& Fingerson, 2001).

\section{Procedure}

Participants. The study adopted a purposeful sampling selection process (Patton, 2002). A recruitment letter was distributed by email to all the families of the local Learning Disabilities Association. The letter stated the purpose of the study and these participation criteria: The student currently used AT at school, preferably on a single laptop; was formally identified as having an LD; and was in Grades 4-8. Those who responded, and who met the criteria, were invited to participate in small focus groups. Respondents were notified by email and telephone of their inclusion in the study and assigned a Saturday to attend based on the child's age. Table 1 identifies the characteristics of the student participants. As the study was not conducted through a school board or a clinic, the parents provided this information. No medical or school records were accessed. Participants attended public school systems (non-denominational and Catholic) that are funded equally by the Ministry of Education in Ontario.

Table 1.

Student Participants

\begin{tabular}{|c|c|c|c|c|c|c|c|c|}
\hline \multirow[b]{2}{*}{ Gender } & \multicolumn{3}{|c|}{$\begin{array}{l}\text { Focus Group } 01 \\
\text { Sat. Jan 08, } 2011\end{array}$} & \multicolumn{2}{|c|}{$\begin{array}{l}\text { Focus Group } 02 \\
\text { Sat. Jan 15, } 2011\end{array}$} & \multicolumn{3}{|c|}{$\begin{array}{l}\text { Focus Group } 03 \\
\text { Sat. Jan 22, } 2011 \\
\end{array}$} \\
\hline & $M$ & $M$ & $M$ & $M$ & $M$ & $F$ & $M$ & $M$ \\
\hline Age & 10 & 10 & 9 & 13 & 12 & 10 & 11 & 10 \\
\hline Grade & 5 & 5 & 4 & 8 & 7 & 5 & 6 & 5 \\
\hline Diagnosis & DYS & DYS & $\begin{array}{l}\text { ADHD, } \\
\text { DYSG }\end{array}$ & ASB, LD & LD & NVLD & LD & CLD \\
\hline $\begin{array}{l}\text { Years with } \\
\text { laptop }\end{array}$ & 2 & 2 & 1 & 6 & 3 & 2 & 2 & 1 \\
\hline $\begin{array}{l}\text { Public/ } \\
\text { Catholic }\end{array}$ & C & C & C & $P$ & $\mathrm{P}$ & C & $\mathrm{P}$ & $P$ \\
\hline
\end{tabular}

Note: $\mathrm{DYS}=$ dyslexia; $\mathrm{ADHD}=$ attention-deficit/hyperactivity disorder; $\mathrm{DYSG}=$ dysgraphia; $A S B=$ Aspberger's syndrome; $L D=$ learning disability; NVLD=non-verbal learning disability; $C L D=$ communication learning disability.

Data collection. Data was collected outside of school in a neutral community setting. Signed consent forms were collected before the focus groups.

For the eight student participants, three focus groups lasting 30-60 minutes were conducted with two to three participants each. One parent focus group with six 
participants took place on the final Saturday of data collection; an additional two parent responses were provided via email for a total of eight parents.

All the students first participated in a one-hour workshop designed to provide an educational benefit to the participants. The workshop encouraged students to use their AT more often at home or school with a better understanding of how the programs worked. We felt it prudent to offer the workshop as an incentive to parents to bring their children to the focus group rather than to other recreational activities on a Saturday. Parents were provided a handout that explained the workshop content step by step, so that they might support their child at home. The workshop was not a data source for this study. After the workshop a 20-minute refreshment break was scheduled. During the break, team-building activities (pool and air hockey) took place to enable students to become comfortable with each other, the note taker and the first author.

Data was collected using the focus group questions (see Appendix) via digital audio recording and written back-up notes by a note taker. The first author was the moderator of each focus group. Follow-up prompts (e.g., Can you tell me more?) were used when participants gave limited responses.

\section{Data Analysis}

We used investigator triangulation, research reflexivity, and working collaboratively to address issues of credibility and trustworthiness (Brantlinger et al., 2005; Patton, 2002). Self-reflexivity was combined with the first author's experiences from working with students with LD and a personal perspective as an insider with a disability.

In order to enhance reliability, the voices of students and parents were included through direct quotations. Each participant was given a random identity number e.g., S27 is Student number 27, and P1 is Parent number 1. The following steps were performed in the data coding process: (a) All student responses were merged into one document organized by question. (b) The first author, independently, repeatedly read the merged document assigning codes to phrases; similar phrases were grouped and assigned a category label. For example, the student comment, "I can do more things by myself.... When I am doing my homework, my mom would have to help me. Now I have my computer, I can actually have it read to me, so I can do it myself" (S27) was coded By myself; other similar codes were grouped and given the category label Independence. (c) The first author, in collaboration with the second author, grouped similar categories into an overarching theme, in this case, Students' Self-Perceptions as Learners. The parent group responses were coded in a similar fashion. (d) The overarching themes were analyzed for similarities between the student and parent responses. (e) A check on the consistency of coding was performed by having a third independent rater who coded three of the ten questions $(2,5$, and 8$)$ from the student focus group transcripts and the entire parent focus group transcript. The independent rater developed her own codes, categories, and themes. The following is an example of how consistency of coding was evaluated: "It makes me feel smarter, not dumb" (S23), was coded by the first author as Smarter. This code was categorized, along with similar codes, as Self-confidence. In collaboration with the second author this category was placed within the theme of Students' Self-Perceptions as Learners. The independent rater developed her own codes 
and categories and placed this phrase in a category labeled Growth in confidence. We compared her coding and categorization of phrases to ours to see if the pattern of placement of utterances was similar. The pattern was similar and the labels given to the codes and categories and themes were largely synonyms.

\section{Results}

Themes from the student and parent focus groups are summarized in Table 2.

Table 2.

Themes from Focus Groups

\begin{tabular}{ll}
\hline Student responses & Parent responses \\
\hline Theme 1. Perceived benefits & Theme 1. Advocacy \\
Made work easier & Vigilance \\
Reduced frustration & Monitoring \\
Able to keep up & Gathering resources \\
Less handwriting & \\
Theme 2. Students' self-perceptions as & Theme 2. Parents' perceptions of children as \\
learners & learners \\
Self-confidence & Self-confidence \\
Independence & Independence \\
Inclusion vs. exclusion & Academic achievement [self-reported] \\
Problem-solver & Problem-solvers \\
Theme 3. Barriers and challenges & Theme 3. Barriers and challenges \\
Space & Lack of communication \\
Equipment & Lack of resources \\
Training & Lack of training (students/parents) \\
Teachers & Lack of teacher knowledge (LD/AT) \\
\hline
\end{tabular}

\section{Student Responses}

Students and parents frequently used the terms computer or laptop to refer to the laptop with AT rather than using the term AT or the specific software (WordQ, Co:Writer, Kurzweil 3000, and Dragon NaturallySpeaking). It is likely that both students and parents used these terms because they were making a comparison between how their situation had been at home or school before the student was diagnosed with LD to how it was after the student was diagnosed and had received the laptop with AT. The questions asked in the focus groups used terms such as, technology, programs (software), and computer.

Perceived benefits. Students' responses suggested their thoughts about school were generally positive as a result of using the computer with AT:

With your computer, it makes school easier because, say you have a few bars and the rest are level and high, and your spelling and writing is down. The computer is like putting up a high jack up under the two bars and then lifting them up to level them up 
with everything else [using hands to show what he meant]. So everything else is level. (S22)

More than one student stated that they found school was easier and less frustrating as a result of the perceived benefit of the laptop with AT. Additionally, levels of frustration were reduced:

Computers make it easier and less frustrating to write, so you don't really have to think about the things that you are not good at. Because the things you are not good at, the computer makes you better at them and helps you. (S22)

Students' ability to keep up with their classes and not feel left behind was also part of this theme: "It feels like school without my computer. I was always behind, I couldn't catch up, stuff like that. And now that I have it, I feel like it is a lot easier and it is faster" (S28). Another student said he felt better "because it was easier, and it was better than failing all the time" (S23).

Students' self-perceptions as learners. The students' self-reported increased independence was clear from the three student focus groups, whether it related to homework completion, increased organization and the ability to locate assignments to hand in, or their decreased reliance on their teacher. They stated that their independence had increased:

I can do more things by myself, and when I am doing my homework ... my mom, she would have to come over and help me with the words. But now that I have my computer I can ... just have it read to me, so I can do it myself. (S27)

Although the students still required support, they reported being able to perform school related tasks more independently.

Probably if I didn't have my computer to work on, it would be really hard ... I would be, like, having my hand up a lot and asking my teacher, like, um, "What was that?" I need help, and when she also has the 23 other students to look after, and the Grade 4s and the other Grade 5s, it is a little difficult for her. (S27)

One student was asked how having the computer made him feel, he responded: "Like I was left out and I was behind. But now with my computer it helps with my learning, and it really helps" (S27). These statements describe a feeling of inclusion versus exclusion, increased self-confidence and less teasing:

Before I got my laptop, it was kind of hard 'cause people made fun of me.... I was falling behind a lot because I was extremely slow, but since I got my laptop I have kept on top of things and not been falling behind. (S22)

Most students had a positive identification related to having an LD: "It is a different way of learning" (S25). "It doesn't mean you can't learn, it means you have problems. All you need is a little-like riding your bike the first time, you need help. Someone pushes you, and that is pretty much what the computer does" (S22).

It means to me that I just learn slower than others and because I have a learning disability. I don't read as fast or write as fast as others, so it is not really different from anyone else- - I just can't read and write as fast. (S27)

One reported change in students' self-perceptions as learners was increased confidence: 
I kind of feel good ... It depends on what the subject is, and it depends on what my idea might be, say it is a speech we have to write about something we feel strongly about. I was pretty excited about that. (S22)

When asked: "How has your self-perception (how you feel about yourself) changed since getting your technology?" a student responded, "It makes me feel smarter, not dumb. Because I feel I can't learn anything when I write. With the computer I feel smarter" (S23).

Other students used words and phrases such as "excited" or "look forward to" when describing how they felt about a new assignment because of the laptop with AT. A key finding was the students' self-proclaimed identity as problem-solvers: "I just say, 'Time to boot up the computer,' and whatever the subject is, say it is social studies, I boot up the program that makes it easiest, like Kurzweil or WordQ" (S22).

In reference to his disability, one student mentioned having dyslexia is like another object to move through: "It is just like a snow plough when you have ice blocking and you need to plough it. You just need to move the obstacles out of the way" (S22).

Barriers and challenges. Students spoke about many barriers associated with using their equipment at school including: equipment failure, ownership and upkeep, and physical space for computer set-up. Viruses, extended time for repair, and printer malfunctions were mentioned as barriers to completing their work, or the cause for having to redo completed work: "One time [the laptop] caught a virus and some things were not working, so it got re-imaged. And other times it was just not working properly and was crashing and not working properly" (S22). Lack of physical space for the set up and maintenance of the equipment was also mentioned: "In my class we have $4 / 5 \mathrm{~s}$ squished in together, and I have a little table that has my printer and my computer.... That is all the space I have, I have no space to put my work down" (S27).

Some students mentioned they did not have an opportunity to use their computer with AT in every class, due to a variety of factors such as space, lack of teacher preparation of electronic materials, or not being allowed to use it. A lack of continued training on existing and new software for both student and teacher were other barriers discussed. When asked what their school could change to make learning better, students talked about a perceived lack of teacher knowledge of AT:

I think if they could train the teachers about the software so that the teachers can help the kids more ... instead of the teach[er] just sending the kids to the EAs or the principal if they had a problem. So the teacher could actually help out more. If they were trained a little bit so they knew the programs, so they know a little bit ... and they can just help out a bit. (S22)

They spoke about difficulties of classes in which they did not have access to their computer. Students also shared stories of teachers who had offered valuable support to acquire necessary equipment and encouraged and inspired students to pursue their learning. "If it wasn't for my vice principal I wouldn't have the computer" (S23). Two students reported how their teachers had encouraged them to seek out other potential areas of strength and how this positive attention influenced their school experience. One participant reported how his teacher had supported him: 
Ms. Smith kind of inspired me. She got me set up with a computer, and she tried to do her best.... Whenever I had a problem she would try to figure it out... She just tried to help me out with as much as she could with my computer. (S22)

The detailed responses of the children provided access into their understanding of their experiences in using their laptops with AT at school.

\section{Parental Responses}

The parental transcript did not follow as sequential a pattern, veering off into tangents in response to the focus group questions. However, two themes were similar to those from the student focus groups as shown in Table 2.

Advocacy. The theme of advocacy surfaced from their daily experiences as parents of children with LD. The discussion centred on the parents' need to advocate for their children. Only some of the parents had been educated about the process of obtaining information and resources by their child's teacher; others happened upon the information by speaking with other parents:

At the beginning of the situation, when I found out John was dyslexic, I felt like I was out on a sea alone.... I had to learn this thing, and there was not a person around.... Anybody I heard who had a child who was dyslexic, I tracked them down. (P1)

This parent's emotional response was echoed by that of other parents as they discussed what it was like to advocate on behalf of their children to obtain equipment. Some parents had experiences that demonstrated teachers and school administrators were working together with the parents. Other parents referred to themselves as "pit bulls" and a "thorn in their side" [of their respective school boards] in order to get the attention they required for their children:

I am a pit bull just like you. If I had let go, they wouldn't have done what they needed to do, either. So, I mean, this happened in Grade 3-I had a great teacher that was an amazing teacher.... She identified him, and if it hadn't been for her-I can remember crying in her class, "Please help my son because if you don't, I don't know what I am going to do." (P2)

More than one parent felt that they should not have to fight for the needs of their children. By participating in the focus group they hoped to demonstrate that they wanted to cooperate and work together for the benefit of the children: "We shouldn't have to advocate for our kids to get equal access to the tools they need for learning. Kids are different, they should know that" (P3).

Some parents reported positive experiences with teachers and school administrators, while others had negative experiences. Some had received training on the software applications, and others had not. Parental views were strongly stated.

Parents' perceptions of their children as learners. Parents described positive changes in their child's learning behaviour, attributing the changes to the child's use of a laptop with AT. Parents spoke of increased grades, improved self-esteem and selfconfidence as well as independence, and increased abilities to problem solve: 
As far as his grades, the laptop has immensely improved everything... It would be a screaming match with me for hours and hours [before the laptop]. It builds character-his self-esteem has improved immensely because he knows he can do it, he has the tools to do it, and his grades have improved immensely. He came home and said, "I got an A- in two assignments" yesterday. His self-esteem has improved dramatically because of the laptop. (P2)

A parent whose child had used a laptop for one year encouraged the other parents:

See, because I pushed and he got his laptop in January of last year, his Grade 4 teacher was amazing, so he loved Grade 4 . He had a great time, and he was doing very well. His marks dramatically improved with the laptop. (P3)

In addition to self-reported increased confidence for academic tasks, parents reported on their children's increased independence:

She is definitely more confident in her work. She sees how the computer makes the work much easier and that the programs can assist her with things that she would have previously had to ask for parent/teacher assistance on. She is much more able to complete her work on her own. (P7)

Due to his child's need to solve issues with their computer or other academic challenges, one parent felt that his child was good at problem solving or "work-arounds." He felt this was an advantage that students gained from having a disability, which might benefit these students in university where critical thinking is required: "If you are the person who has had the internal journey, and you have had to find ways of getting around problems and work-arounds... We all know these kids are good with the work-around" (P4).

Barriers and challenges. The majority of the parental responses fit into this theme. Barriers included the length of time for initial psycho-educational assessments, ongoing issues with provision of the equipment, restrictions on laptops traveling back and forth to school, and lack of teacher preparation or comfort with laptop and software use:

George is not allowed to bring [the laptop] out of the school and has to leave his at school ... It has to be locked up every night. So he has use of the special ed[ucation] stuff at the one school and goes back to his home school, and he has to set it up and unlock it and everything else.... It doesn't travel with him. (P6)

She likened it to being prevented from using a physical apparatus required for daily functioning: "Here is your robotic arm, but we are going to keep it at school so you can use it here" (P6). Another parent added, "A really good example-like here are your glasses, but you can only use them at school" (P1). The first parent responded, "And he is frustrated like crazy, and it drives me nuts how he can't do his homework" (P6).

This specific group of parents perceived that the provision of services for students with LD differed between the two local school boards:

I wonder if there could be more communication between the school boards because, as a person who has a child in the Catholic board - and we switched to the Catholic board specifically because my son is dyslexic - we felt there would be more resources there. And we were right, we have been thrilled with the resources... None of these kids should be disadvantaged. I am sure that is not the intention of the board, 
but if they realize... We are taking good care of [the laptop], nobody is breaking this equipment. (P1)

Parents also spoke about the lack of communication between home and school. One parent did not understand how the computer was intended to help her child:

At first it was the explanation of why she had use of a computer and the understanding of why by the other students-especially because she received hers part way through Grade 4, which is a little less common. This has really not changed much, as the laptop is not used in class very often. (P7)

Some parents shared that teachers they met had little knowledge of LD or other disabilities:

Both of my kids have learning issues, and there are no resources there. I get this blank face from the special ed[ucation] teacher like they have never heard of a special ed[ucation] issue; these people are not equipped to deal with these kids who have learning disabilities. Bright kids, talented, capable. (P1)

Some parents had positive experiences with classroom teachers, but these were often inconsistent and depended on the classroom teacher's comfort with the technology:

Make sure they are using the laptop in any possible learning situation. I find that the teachers may not fully understand how the programs work, so they find it almost bothersome to have to prepare information for one student in such a fashion that it can be used with the assistive technologies provided to the students. (P3)

A common barrier was the differences in the amount of training parents and children received in the use of laptop software:

When John got his laptop, there was training for his programs.... I attended all three, and that was very helpful to see what the programs do. Now funding for training [is gone]. He was supposed to have two days of training this year, but that has been cut. So the resources have been cut off through the board. (P1)

Overall, parents were frustrated by the various barriers that their children encountered in using the laptop with AT.

Hearing from the parents and their children provided an authentic rendering of the situations faced daily by families in this study.

\section{Discussion}

Students' frequently participate in qualitative or quantitative research; however, their voices and opinions are infrequently heard (Curtis et al., 2004). By speaking directly to the users of AT, we gathered information to advance our understanding of how elementary students with LD view the use of AT. Few children have been asked about their use of new technologies such as WPS (Cullen et al., 2008; Evmenova et al., 2010; Young, 2012). As authors of their stories, the eight students in this study openly shared their feelings about school and the support provided by AT.

Students and parents spoke of how using AT, especially WPS lowered students' concerns with spelling and grammar, as has been noted by other researchers (Goddard \& Sendi, 2008; Santangelo et al., 2008, Young, 2012). Parents perceived that their children 
were able to focus on writing without worrying about spelling and grammar and that this enabled students to accomplish more school work independently. This finding is similar to those of parents who reported that their children gained more independence when using AT (Tam et al., 2005; Young, 2012). Students and parents commented on the process of doing schoolwork and the change in the quality of their work because the students had a laptop with AT, but they usually did not name the specific software. As researchers we were primarily interested in the students' perceptions of themselves as learners and whether it had changed because of using AT. When interpreting these results one has to keep in mind that students might be overestimating their abilities. Some researchers have found that to be the case for students with LD (Klassen, 2002; Klassen \& Lynch, 2007). As we did not have access to school records, we were unable to examine if this was the case in our study. Due to the age of the student participants, the parents' perspectives offered additional information to substantiate claims made by the students.

These students with LD described themselves positively using words and phrases such as "creative," "hard-working," "problem-solver," "likes learning," and "feels good about learning." Their parents also commented on the "increased self-confidence," "selfesteem," "independence," and "problem-solving" abilities as beneficial outcomes from students' use of laptops with AT.

Although academic self-concept and self-efficacy were not formally assessed in this study, the responses of the students and parental statements could be interpreted as a possible change in academic self-concept or self-efficacy beliefs. As stated by this student:

With a learning disability it doesn't mean you have a learning disability with everything. It is only with one certain area, and not everybody is good at everything. So you might be good at, say, science and building things ... but you can't read and write very well... You need challenges or else you can't live or work too well. (S22)

\section{Limitations}

The limitations of this study included a convenience sample due to the recruitment through the local Learning Disabilities Association. As the participants were volunteers they may not have been representative of all families with students with LD. The students' responses may have been influenced by their participation in the workshop.

The interpretation of responses solicited by open-ended questions used in focus group research adds to the difficulty of data analysis.

\section{Implications for Practice}

The theme of Barriers and Challenges highlights areas that could be addressed to improve school for students with LD and to support their parents. Writing is an important curricular area in elementary school. Participants described positive benefits from AT, suggesting there needs to be a stronger focus on its use in the classroom (Rose \& Meyer, 2002). Some changes are common sense, such as providing a student with a table for their equipment. Others require restructuring teacher education programs to ensure all teachers have sufficient knowledge of learning disabilities and have skill in and 
knowledge of AT. This has been recommended by other researchers (Forgrave, 2002; Troia, Shankland, \& Wolbers, 2010) as well as sustained and relevant training for students using AT (Handley-More et al., 2003).

Parents' responses about the assessment process and the provision of equipment as a result of the psycho-educational assessment were areas in which there was a lack of consistency. Communication from the educational system to parents was problematic and is similar to what has been reported in the literature (Valle, 2011; Waggoner \& Wilgosh, 1990). Parents discussed their need to be advocates and the challenge of being involved in their child's education. As volunteers for this study, these parents may have already been functioning well, and yet it is clear from their statements that they faced challenges and barriers as parents of children with LD. Teachers and administrators could consider Valle's (2011) findings on how parents are perceived and could reflect upon the degree this might apply to their communication with parents.

Implications for future research include the need for researchers to involve children as active participants in research given the powerful narrative they can offer about their own experiences. Secondly, replicating this study with a larger sample size and conducting the study over a longer period. Additionally, by adding teacher interviews and classroom observation to a qualitative study a more robust data set could be obtained. Ideally conducting an experimental study in which students' academic self-concept or self-efficacy is measured with a standardized instrument prior to receiving laptops with AT, followed by subsequent measurement of academic self-concept or self-efficacy might offer more conclusive data.

\section{Conclusion}

This qualitative study addresses a gap in the research through eliciting elementaryschool-aged students' accounts of their interactions with AT. Insight was gained into their self-perceptions as learners with LD and into the barriers and challenges they encountered. The parent focus group provided a deeper understanding of how their children were affected by the provision of AT. Children were invited to participate in research with them rather than performing research on them (Robbins, 2003). Capturing the students' voices and the parents' observations of their children, along with their views of issues related to use of AT provided an insider's perspective.

\section{References}

Batorowicz, B., Missiuna, C. A., \& Pollock, N. A. (2012). Technology supporting written productivity in children with learning disabilities: A critical review. Canadian Journal of Occupational Therapy, 79(4), 211-224. doi:10.2182/cjot.2012.79.4.3

Bickman, L., \& Rog, D. (1998). Handbook of applied social science methods. Thousand Oaks, CA: Sage.

Brantlinger, E., Jimenez, R., Klinger, J., Pugach, M., \& Richardson, V. (2005). Qualitative studies in special education. Council of Exceptional Children, 71(2), 195-207.

Burden, R. (2008). Is dyslexia necessarily associated with negative feelings of self-worth? A review and implications for future research. Dyslexia: An International Journal of Research and Practice, 14(3), 188-196. doi:10.1002/dys.371 
Schock \& Lee

Conroy, H., \& Harcourt, D. (2010). Informed agreement to participate beginning the partnership with children in research. Early Child Development and Care, 179(2), 157-165. doi: $10.1080 / 003004430802666973$.

Co:Writer [Computer software]. (n.d.). Volo, IL: Don Johnston Incorporated. http://donjohnston.com /cowriter

Cullen, J., Richards, S., \& Frank, C. (2008). Using software to enhance the writing skills of students with special needs. Journal of Special Education Technology, 23(2), 33-44.

Curtis, K., Liabo, K., Roberts, H., \& Baker, M. (2004). Consulted but not heard: A qualitative study of young people's views of their local health service. Health Expectations, 7, 149-156.

Dragon NaturallySpeaking [Computer software]. (n.d.). Burlington, MA: Nuance Communications. http://www.nuance.com/dragon

Eder, D., \& Fingerson, L. (2001). Interviewing children \& adolescents. In J. Gubrium \& J. Holstein (Eds.), Handbook of interview research: Context \& method (pp. 181-202). Thousand Oaks, CA: Sage

Elbaum, B., \& Vaughn, S. (2006). In H. L. Swanson, K. R. Harris, \& S. Graham (Eds.), Handbook of learning disabilities. New York, NY. The Guilford Press.

Evmenova, A., Graff, H., Jerome, M., \& Behrmann, M. (2010). Word prediction programs with phonetic spelling support performance comparisons and impact on journal writing for students with writing difficulties. Learning Disabilities Research, 25(4), 170-182. doi: $10.2307 / 30035513$

Forgrave, K. (2002). Assistive technology: Empowering students with learning disabilities. The Clearing House, 75(3), 122-126. doi:1080/0098650209599250

Graham, S., \& Harris, K. R. (2000). The role of self-regulation and transcription skills in writing and writing development. Educational Psychologist, 35(1), 3-12. doi:10.1207/515326985EP3501_2

Goddard, Y., \& Sendi, C. (2008). Effects of self monitoring on the narrative and expository writing of four fourth-grade students with learning disabilities. Reading \& Writing Quarterly, 24(4), 408-433. doi:10.1080/10573560802004514

Haager, D., \& Vaughn, S. (1995). Parent, teacher, peer self-report of the social competence of students with learning disabilities. Journal of Learning Disabilities, 28(4), 205-215. doi:10.1177/002221949502800403

Handley-More, D., Deitz, J., Billingsley, F., \& Coggins, T. (2003). Facilitating written work using computer word processing and word prediction. American Journal of Occupational Therapy, 57, 139-151. doi:10.5014/ajot.57.2.139

Hayes, J. (2004). A new framework for understanding cognition and affect in writing. In R. Ruddell \& N. Unrau (Eds.), Theoretical models and processes in reading (5th ed., pp. 1399-1430). Newark, NJ: International Reading Association.

Klassen, R. (2002). Writing in early adolescence: A review of the role of self-efficacy beliefs. Educational Psychology Review, 14(2), 173-203. doi:10.1023/A:1014626805572

Klassen, R., \& Lynch, S. (2007). Self-efficacy from the perspective of adolescents with LD and their specialist teachers. Journal of Learning Disabilities, 40(6), 494-507. doi:10.1177/00222194070400060201

Kurzweil 3000 [Computer software]. (n.d.). Natick, MA: Kurzweil Education. https://www.kurzweiledu.com

Learning Disabilities Association of Canada. January 30, 2002, Re-endorsed on March 2, 2015. Retrieved from http://www.ldac-acta.ca/

91 Exceptionality Education International, 2016, Vol. 26, No. 1 
Lewis, R., Graves, A., Ashton, T., \& Kieley, C. (1998). Word processing tools for students with learning disabilities. Learning Disabilities Research \& Practice, 13, 95-108.

MacArthur, C. A. (1998). From illegible to understandable: How word recognition and speech synthesis can help. Teaching Exceptional Children, July/August, 66-71.

MacArthur, C. A. (1999). Word prediction for students with severe spelling problems. Learning Disability Quarterly, 22, 158-172. doi:10.2307/1511283

MacArthur, C. A., \& Graham, S. (1987). Learning disabled students' composing under three methods of text production: Handwriting, word processing and dictation. The Journal of Special Education, 21(3), 22-42. doi:10.1177/002246698702100304

Madriz, E. (2000). Focus groups in feminist research. In N. Denzin \& Y. Lincoln (Eds.), Handbook of qualitative research (2nd ed., pp. 835-850). Thousand Oaks, CA: Sage Publications.

Mirenda, P., Turoldo, M., \& McAvoy, C. (2006). The impact of word prediction software on the written output of students with physical disabilities. Journal of Special Education Technology, 21(3), 5-12.

Morgan, D. (1996). Focus groups. Annual Review of Sociology, 22, 129-153. doi:10/1146 /annurev.soc.22.1.129

Patton, M. (2002). Qualitative research \& evaluation methods. Thousand Oaks, CA: Sage.

Peterson-Karlan, G., Hourcade, J., \& Parette, P. (2008). A review of assistive technology and writing skills for students with physical and educational disabilities. Physical Disabilities: Education and Related Services, 26(2), 13-32.

Raskind, M., Margalit, M., \& Higgins, E. (2006). "My LD": Children's voices on the Internet. Learning Disability Quarterly, 29(4), 253-268. doi:10.2307/30035553

Robbins, J. (2003). The more he looked inside the more Piglet wasn't there: What adopting a sociocultural perspective can help us see. Australian Journal of Early Childhood, 28(2), 1-7.

Rose, D., \& Meyer, A. (2002). Teaching every student in the digital age. Alexandria, VA: Association for Supervision and Curriculum Development.

Ross, D. (2004). Engaging students' voices in the Jewish day school: Perspectives of learning disabled students. Journal of Jewish Education, 70(1/2), 51-59. doi:10.1080/0021624040700108

Santangelo, T., Harris, K., \& Graham, S. (2008). Using self-regulated strategy development to support students who have trubol giting thangs into werds. Remedial \& Special Education, 29(2), 7889. doi:10.1177/0741932507311636.

Shein, F., Nantais, T., Nishiyama, R., Tam, C., \& Marshall, P. (2001, July). Word cueing for persons with writing difficulties: WordQ. Paper presented at 16th Annual Conference on Technology for Persons with Disabilities, Los Angeles, California. Retrieved from http://www.csun.edu/ hfdss006/conf/2001/proceedings/0126shein.htm

Silio, M., \& Barbetta, P. (2010). The effects of word prediction and text-to-speech technologies on the narrative writing skills of Hispanic students with specific learning disabilities. Journal of Special Education Technology, 25(4), 17-33.

Swanson, H., Harris, K., \& Graham, S. (2003). Handbook of learning disabilities. New York, NY: Guilford Press.

Tabassam, W., \& Grainger, J. (2002). Self-concept, attributional style and self-efficacy beliefs of students with learning disabilities with and without attention deficit hyperactivity disorder. Learning Disability Quarterly, 25(2), 141-151. doi:10.2307/1511280 
Tam, C., Archer, J., Mays, J., \& Skidmore, G. (2005). Effectiveness of word cueing for children with physical and learning disabilities. Canadian Journal of Occupational Therapy, 72(5), 301308. doi:10.1080/10400430903175473.

Tam, C., \& Wells, D. (2009). Evaluating the benefits of displaying word prediction lists on the personal digital assistant at the keyboard level. Assistive Technology, 21, 105-114. doi:10.1080/10400430903175473

Torrance, M. (2007). Cognitive processes in the development of writing expertise. In M. Sénéchal (Ed.), Encyclopedia of Language and Literacy Development (pp. 1-7). London, ON: Canadian Language and Literacy Research Network. Retrieved from http://www.literacyencyenclopedia.ca/pdfs/topic.php?topID $=254$

Torrance, M., \& Jeffrey, G. (1999). The cognitive demands of writing. Amsterdam, Netherlands: Amsterdam University Press.

Troia, G. (2005). Writing instruction for students with learning disabilities. In C. MacArthur \& S. Graham (Eds.), Handbook of writing research (pp. 321-336). New York, NY: Guilford Press.

Troia, G., Shankland, R., \& Wolbers, K. (2010). Reluctant writers and their teachers. In G. S. Troia (Ed.), Putting writing research into practice: Applications for teacher PD (pp. 70-90). New York, NY: Guilford Press.

Tumlin, J., \& Heller, K. W. (2004). Using word prediction software to increase typing fluency with students with physical disabilities. Journal of Special Education Technology, 19(3), 5-12.

Valle, J. W. (2011). Down the rabbit hole: A commentary about research on parents and special education. Learning Disability Quarterly, 34(3), 183-190. doi:10.1177/0731948711417555

Waggoner, K., \& Wilgosh, L. (1990). Concerns of families of children with learning disabilities. Journal of Learning Disabilities, 23, 97-98. doi:10.1177/002221949002300204

Williams, S. (2002). How speech-feedback and word-prediction software can help students write. Teaching Exceptional Children, 34(3), 72-78.

WordQ [Computer software]. (n.d.). Toronto, ON: Quillsoft Ltd. http://www.goqsoftware.com

Young, G. D. (2012). Examining assistive technology use, self-concept, and motivation, as students with learning disabilities transition from a demonstration school into inclusive classrooms. Electronic thesis and dissertation repository. Paper 1054. http://ir.lib.uwo.ca/etd/1054

Zeleke, S. (2004). Self-concepts of students with learning disabilities and their normally achieving peers: A review. European Journal of Special Needs Education, 19(2), 145- 170. doi:10.1080/08856250410001678469

\section{Disclosure}

The authors and their research programs are not in any way affiliated with or funded by the makers or distributors of any product named in this article. Brand names are reported only for the purpose of factual accuracy, and our use of such products for research purposes does not constitute an endorsement of any particular brand or vendor.

\section{Authors' Note}

Correspondence concerning this article should be addressed to Robin Schock, St. Lawrence College, 100 Portsmouth Ave. Kingston, ON, K7L 5A6, Canada Email: rschock@sl.on.ca 


\section{Appendix: Focus Group Questions}

\section{Student Questions}

1. Often when we meet someone for the first time, we might describe ourselves in a certain way to get to know these people better. I want to understand what you think of yourself as a learner. What word or words would you use to describe yourself as a learner?

2. Everyone here has been given assistive technology. How has your self-perception (how you feel about yourself) changed since getting your technology? Has it made doing your school work any different? How?

3. What does it mean to have a learning disability?

4. If I were to walk into your classroom on Monday, would I see you using your computer? If not, when would you be using it? For what? Which class?

5. Would you say school is easy or hard for you? Why? Tell me what is easy or hard.

6. How do you feel about using your technology/laptop in class?

7. How does using your laptop in school make you feel? Tell me more about that?

8. What could the school change to make learning better for you? If you could change one thing to make learning better, what would that be?

9. Without telling us the name of the teacher, everyone please think about something a teacher has done that made using your laptop or programs easier to use in class.

10. Tell me how you feel when being given a new assignment in class, and why? Maybe you might feel confident, nervous, scared?

\section{Parent Questions}

1. Tell me about your son or daughter's experience using technology at home.

2. Are you aware of any differences in how your child uses their laptop/computer at home and at school?

3. Since your child has started using assistive technology, are there any changes in the way they feel about themselves as learners?

4. How do you feel your son's or daughter's self-perceptions have changed, if at all, by using assistive technology for writing?

5. If they have not changed, what barriers might be contributing to this?

6. How could educators better support your child's use of their laptop, i.e., WordQ or Co:Writer? Do you have any examples to share?

7. From your perspective, what could you change about your child's learning environment at school to help your child's self perceptions as a learner improve?

8. What issues did you encounter when your child started using their laptop? If these issues have changed, how have they changed? 